\title{
Fenomenologia, ética e educação: uma análise a partir do pensamento de Husserl
}

Adão José Peixoto

Professor da Faculdade de Educação da Universidade Federal de Goiás Doutor em Educação pela USP

\section{Resumo}

O texto apresenta uma análise sobre a fenomenologia husserliana e sua crítica ao objetivismo, que tem orientado a filosofia, as ciências e as demais práticas humanas. Inicia-se com a apresentação da origem da fenomenologia, seguida da crítica ao objetivismo, da concepção husserliana sobre a ética e das contribuições destas concepções para a educação. É uma pesquisa bibliográfica realizada a partir de obras de Husserl e de comentadores do pensamento deste filósofo.

Palavras-chave: Fenomenologia; Husserl; Ética; Educação.

\begin{abstract}
The paper presents an analysis of Husserl phenomenology and his critique of objectivism that has guided philosophy, science and other human practices. It begins with the presentation of the origin of phenomenology, followed by the critique of objectivism, Husserl conception about ethics and the contributions of these conceptions for education. It is a bibliographical research realized from Husserl works and commentators of the thought of this philosopher.
\end{abstract}

Key-words: Phenomenology; Husserl; Ethics; Education. 


\section{Introdução}

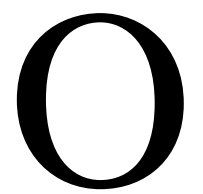

pensamento husserliano exerce uma grande influência não só na filosofia, mas também nas ciências, em especial nas ciências humanas. Husserl foi o fundador da fenomenologia. Ao se aventurar na elaboração do pensamento fenomenológico, Husserl travou um amplo e duro debate com as concepções que impuseram às ciências e à própria filosofia uma orientação denominada por ele de objetivismo, que ignora as especificidades das ciências humanas e da filosofia, contribuindo para o esquecimento da dimensão humana. Husserl esforçou-se para recuperar essa especificidade e afirmar a necessidade de se colocar o lebenswelt (mundo da vida) como referência da práxis filosófica, científica e social. Ao abordar essa questões, Husserl elaborou também uma nova perspectiva ética como referência do agir humano. Acreditamos que as concepções de Husserl trazem também contribuições para se repensar a própria educação. Neste sentido, propomos apresentar aqui uma análise introdutória sobre a crítica de Husserl ao objetivismo, a sua concepção sobre ética e as contribuições dessas concepções para a educação.

\section{A fenomenologia husserliana, a possibilidade do conhecimento e a crítica ao objetivismo}

A palavra fenomenologia tem sua origem em duas outras palavras gregas: phainomenon, que significa "o que se mostra”, “o que se manifesta”, e logos, que significa “discurso”, “ciência”. Portanto, etimologicamente, fenomenologia significa o estudo ou ciência do fenômeno.

Na aula inaugural em Fribugo, Husserl (apud MOREIRA, 2002, p. 64) assim se referiu sobre o conceito de fenômeno:

O primeiro e mais primitivo conceito do fenômeno referia-se à limitada esfera das realidades sensorialmente dadas, através das quais a natureza é evidenciada no perceber. O conceito foi estendido [...] para incluir qualquer espécie de coisa sensorialmnte entendida ou objetivada [...]. Inclui então todas as formas pelas quais as coisas são dadas à consciência. Viu-se, 
finalmente, (que o conceito) inclui todo o domínio da consciência com todas as formas de estar consciente de algo e todos os constituintes que podem ser iminentemente mostrados como pertencentes a eles. Que o conceito inclua todas as formas de estar consciente e algo quer dizer que ele inclui também qualquer espécie de sentimento, desejo e vontade, com seu comportamento.

Como se percebe, para Husserl, tudo que existe é fenômeno. Este é a presença real de coisas reais à consciência. Fenômeno é o que aparece diretamente à consciência.

A consciência, na perspectiva husserliana, possui uma essência diferente da essência dos fenômenos. A consciência não se torna mais uma coisa, não se confunde com as coisas, mas dá-lhes significação, mantendose diferente delas.

O que é então o fenômeno nessa concepção? Para Husserl, o fenômeno é a essência. E a essência é a significação ou o sentido que apreendemos de um ser, sua ideia (eidos). Nesse sentido, a filosofia é a descrição da essência da consciência, de seus atos e correlatos, e também das essências das coisas. Por isso, a filosofia é uma eidética, a descrição dos eidos ou essência. Como eidos ou essência é o fenômeno, a filosofia é aqui entendida como fenomenologia.

Para Husserl, fenômenos são as coisas materiais que percebemos e tocamos; as coisas naturais estudadas pelas ciências da natureza (física, química, astronomia, biologia); as coisas ideais, aquilo que é estudado pela matemática (números, figuras geométricas, conceitos como identidade, necessidade) e as coisas criadas pela cultura, pela ação e pela prática humanas (crenças, valores morais, artes, técnicas, instituições sociais e políticas). Todas essas coisas são fenômenos, ou seja, significações ou essências que aparecem à consciência e que são também consciência. Portanto, a fenomenologia é a descrição de todas as essências (eidos) ou significações de todas as realidades materiais, naturais, ideais e culturais; é a descrição de todos os fenômenos. 
O termo fenomenologia foi empregado por vários pensadores antes de Husserl. O primeiro a utilizá-lo foi J. H. Lambert na obra Novo órganon, em 1764, em que fenomenologia aparece como a teoria da ilusão, estudo das fontes do erro. Kant faz referência ao termo em 1770, numa carta a Lambert, em que chama phaenomenologia generalis a disciplina propedêutica que deve preceder a metafisica. Em 1772, novamente o utiliza na carta a Marcus Herz, ao apresentar o plano de uma obra, publicada em 1781 com o título Crítica da razão pura. Mesmo não aparecendo o termo fenomenologia no título, essa obra não deixa de ser uma leitura fenomenológica, pois, “ao entregar-[se] a uma investigação da estrutura do sujeito e das ‘funções’ do espírito, se dá por tarefa circunscrever o domínio do aparecer ou fenômeno” (DARTIGUES, 1973, p. 12).

Foi com a obra Fenomenologia do espírito, de Hegel, que o termo fenomenologia passou a ser de uso corrente no meio filosófico. Para Hegel, o absoluto é cognoscível. Assim, a fenomenologia é uma filosofia do absoluto ou do espírito. Essa filosofia enuncia a verdade do espírito não desvinculada da experiência humana (experiência política, estética, religiosa, jurídica ou prática), mas como parte dessa experiência. Podemos dizer que, para Hegel, a fenomenologia é a ciência que estuda as vicissitudes do espírito, o seu movimento, o caminho que percorre no desenrolar da história.

Entretanto, não foi nem a fenomenologia de Lambert, nem a de Kant e nem a de Hegel que se afirmou como movimento de pensamento com o nome de fenomenologia. O fundador desse movimento foi Edmund Husserl, que sistematizou os fundamentos de uma nova filosofia e de um novo método: a fenomenologia.

Segundo Paul Ricoeur (apud DARTIGUES, 1973, p. 13), “no fundo, a fenomenologia nasceu no momento em que, colocando entre parênteses provisória ou definitiva - a questão do ser, trata-se como um problema autônomo a maneira de aparecer das coisas”. 
Para Merleau-Ponty (1989, p. 2), “a fenomenologia se deixa praticar e reconhecer como maneira ou estilo; ela existe como movimento antes de ter chegado a uma inteira consciência filosófica”. Com isso, Merleau-Ponty quer afirmar que a fenomenologia é um movimento. Ela já existia antes de ter se tornado “consciência filosófica”, ou seja, antes de ter se transformado numa filosofia e numa metodologia. Merleau-Ponty quer dizer também que a fenomenologia não é uma doutrina, nem um conhecimento pronto e acabado, mas um caminho sempre aberto, um constante recomeçar. Essa é também a posição de Husserl (1988, p. 3), investigador criterioso, apaixonado pelo que faz, crítico severo das suas próprias investigações, sempre à procura de maior clareza e fundamentação. Essa preocupação é expressa pelo próprio Husserl (1988, p. 3), por exemplo, no prefácio das Investigações lógicas que, ao comentar os problemas para edição desse texto, afirmou que "dificuldades teóricas, que me surgiram durante a mesma, exigiam profundas reformulações do novo esboço de texto”: Para Giles, "é exatamente por esse motivo que não encontramos em Husserl o sistema acabado, fechado, pois a fenomenologia pretende ser, por essência, a filosofia fundamentada no dinamismo intencional de uma consciência aberta (1989, p. 56).

Por entender a fenomenologia como devir, sempre aberta para as novas conquistas da análise filosófica, e com o rigor que lhe é próprio, é que Husserl se preocupou com a constante autocorreção e superação das suas próprias análises, até que atingissem a fundamentação mais desejada.

Para a fenomenologia, o impulso para a reflexão filosófica não deve partir das concepções já elaboradas, preestabelecidas, dos pré-conceitos, mas das próprias coisas, dos próprios fenômenos. É por isso que a filosofia enquanto fenomenologia é uma autêntica exigência ética, comprometida com a verdade, que rejeita a manipulação da realidade.

A fenomenologia é uma concepção de ciência e de filosofia; é também uma metodologia, um caminho para se atingir um conhecimento rigoroso. É por isso que, segundo Husserl (1990, p. 46), “fenomenologia designa uma 
ciência, uma conexão de disciplinas científicas; mas, ao mesmo tempo e acima de tudo, fenomenologia designa um método e uma atitude intelectual: a atitude intelectual especificamente filosófica, o método especificamente filosófico".

A questão básica posta por Husserl é a da possibilidade do conhecimento, ou seja, como pode o conhecimento estar certo de sua correspondência com as coisas que existem em si, de as atingir? O que possibilita o conhecimento ser uma expressão do real e não uma manifestação de um devaneio, de uma fantasia? O esforço de Husserl foi o de dotar a filosofia de condições para superação desse problema.

A fenomenologia surgiu no início do século XX, contexto de profundas transformações sociais, políticas e culturais, de grande produção intelectual e de difusão das ciências humanas. Época marcada pela influência da dicotomia estabelecida, de um lado, pelo racionalismo e, de outro, pelo empirismo e positivismo.

O racionalismo afirmava o sujeito, mas anulava a experiência. O empirismo afirmava a experiência, mas anulava o sujeito. O positivismo afirmava a objetividade, a comprovação empírica, mas anulava a subjetividade. Essas polaridades expressam uma racionalidade que anula o mundo vivido e com isso distancia a ciência e a filosofia do homem, já que este não é só subjetividade e nem só objetividade. O homem, para a fenomenologia, é uma totalidade que reúne tanto a dimensão subjetiva quanto a objetiva, pois está inserido no mundo e é também por este determinado. A consciência, por exemplo, não é pura consciência, como acreditava o racionalismo, assim como o mundo não é pura objetividade, como acreditavam o empirismo e o positivismo, pois ele só é mundo para o sujeito que lhe dá sentido. Assim, para a fenomenologia toda consciência é consciência de alguma coisa, é intencionalidade, ato de visar, de abarcar algo. A intencionalidade é um transcender, um dirigir-se à outra coisa que não seja a própria consciência. Por isso é vivência, é consciência e mundo. Se é vivência, o que é essa vivência? É toda visada ou ato de visar da 
consciência e seus correlatos. A todo conteúdo visado, a todo objeto (noema), há a correspondência de uma certa modalidade de consciência (noesis). A intencionalidade institui uma interação entre sujeito e objeto, o homem e o mundo, o pensamento e o ser, mostrando que todos os atos psíquicos, tudo o que acontece na mente visa um objeto, e nada ocorre no vazio. É por isso que Husserl afirma que "todo o estado de consciência em geral é, em si mesmo, consciência de qualquer coisa”(2001, p. 50). Desta forma, intencionalidade "não significa nada mais que essa particularidade fundamental e geral que a consciência tem de ser consciência de alguma coisa, de conter, em sua qualidade de cogito, seu cogitatum em si mesma”(HUSSERL, 2001, p. 51). O objeto, por sua vez, só pode ser definido em sua interação com a consciência, por ser sempre objeto-paraum-sujeito. Contrariamente ao que afirma o empirismo, a fenomenologia diz que o objeto só possui sentido para uma consciência. “Assim as essências não existem fora do ato de consciência. Nesse sentido a fenomenologia husserliana busca a descrição dos atos intencionais da consciência e dos objetos por ela visados, ou seja, pela análise noético-noemático”(ZILLES, 2003, p. 173).

Husserl considera o lebenswelt (mundo da vida) como origem e fundamento das ciências objetivas. Segundo Zilles, para Husserl, “se o mundo da vida, por um lado, era a origem das ciências objetivas, por outro, era-lhe claro que tinham esquecido essa origem. Este era, para ele, um momento da crise das ciências. Considerava o mundo da vida como um novo ponto de partida” (2002, p. 48) para o pensar e fazer tanto cientifico como filosófico. O mundo da vida passa a assumir dupla função: “a) a função de fundamento (Bodenfunktion) em relação às ciências e b) a função de fio condutor (LeitfadenfunKtion) para o retorno da fenomenologia à subjetividade constitutiva do mundo" (ZILLES, 2002, p. 48).

É por não ter o mundo vida (lebenswelt) como base da sua orientação que o racionalismo, o empirismo e o positivismo se tornaram construções epistemológicas abstratas. É essa abstração que fez com que estas orientações, em especial o positivismo, se constituíssem, segundo Merleau- 
Ponty, num “pensamento de sobrevoo”, na crença de que a razão e a ciência podem colocar-se soberanamente acima de tudo: "pensamento de sobrevoo, pensamento do objeto em geral - torne a colocar-se num 'há' prévio, no lugar, no solo do mundo sensível” (1989, p. 48). Esse pensamento faz com que “a ciência manipula as coisas e renuncia a habitá-las. Fabrica para si modelos internos delas e, operando sobre esses índices ou variáveis as transformações permitidas por sua definição, só de longe em longe se defronta com o mundo atual” (1989, p. 47). Esse pensamento é o que Merleau-Ponty também denomina de “operatório” (1989, p. 48), uma espécie de artificialismo, pensamento desenraizado da vida e que Husserl chama de objetivismo.

É possível identificar na Fenomenologia de Husserl um projeto de refundação da filosofia e das ciências, em novas bases éticas. Refundação significa aqui restabelecer, recuperar, retomar o sentido que foi perdido. Husserl, na obra A crise da humanidade européia e a filosofia, dedicou-se a analisar a crise vivenciada pela filosofia, pelas ciências e pelo homem europeu. Uma crise de civilização; crise espiritual do ente europeu; crise da Europa como ente cultural. Crise negadora do ente europeu. É uma crise da identidade europeia. Essa identidade em crise de que Husserl fala não é uma identidade restrita à Europa. Ela surgiu na Europa, é uma crise européia, mas também uma crise da civilização ocidental. É por isso que Husserl afirma que

trata-se aqui de uma unidade de vida, de uma ação, de uma criação de ordem espiritual, incluindo todos os objetivos, os interesses, as preocupações e os esforços, as obras feitas com uma intenção, as instituições e as organizações. Nelas atuam os indivíduos dentro de sociedades múltiplas, de diferentes graus de complexidade, de famílias, raças, nações, nas quais todos parecem estar interior e espiritualmente vinculados uns aos outros e, como disse, na unidade de uma estrutura espiritual (HUSSERL, 2002, p.. 70).

Por mais diferentes que as sociedades ocidentais sejam, elas conservam no plano espiritual essa identidade em crise, negadora da identidade européia autêntica, as "penetra e transcende as diferenças 
nacionais” (HUSSERL, 2002, p. 71). É a identidade europeia inautêntica personificada no capitalismo e suas formas de organização e reorganização do capital, no espírito objetivista e cientificista, na exclusão social, no consumismo, no individualismo e na banalidade da vida humana. Para Husserl, esse é o "télos espiritual da humanidade européia, no qual está compreendido o télos particular das nações singulares e dos homens individuais. Esse télos situa-se num infinito, é uma ideia infinita, para a qual tende, por assim dizer, o vir-a-ser espiritual global. À medida que, no próximo desenvolvimento, se torna consciente como télos, torna-se também meta pratica da vontade” (HUSSERL, 2002, p.72).

Para Husserl, o ente europeu, télos espiritual da humanidade europeia, a identidade europeia autêntica tem um lugar de nascimento espiritual preciso. Tal lugar é a Grécia Antiga do século VII e VI a. C.

nela surge uma nova atitude de indivíduos para com o mundo circundante. E, como conseqüência, irrompe um tipo totalmente novo de criações espirituais, que rapidamente assumiu as proporções de uma forma cultural bem delimitada. Os gregos chamaram-na filosofia [...] este termo é um outro nome para ciência universal, a ciência da totalidade do mundo, da unidade total de todo o existente (2002, p. 73).

Husserl designa como filosofia "uma classe especial de criações culturais (kulturgebilde) (HUSSERL, 2002, p. 73). Essas criações têm um modo de ser e uma temporalidade totalmente diferentes das outras formas culturais já existentes, “como o comércio, a indústria, a produção de mercadorias, de objetos, de coisas, que são criações culturais que têm uma existência transitórias. Diferentemente, as criações culturais proporcionadas pela filosofia "não é algo real, mas ideal; mais ainda, o que assim é adquirido, com seu valor e sua verdade, torna-se a matéria para a possível criação de idealidades de nível superior” (HUSSERL, 2002, p. 75).

Na sua origem, a filosofia assume a função de reflexão livre, universal, teórica e desinteressada, sem se prender a interesses particulares, imediatistas e práticos. A filosofia motivada pelo thaumátzein platônico e 
aristotélico formula questionamentos gnosiológico-críticos, inaugurando um novo espírito de livre crítica orientado para tarefas infinitas.

Essa função da filosofia foi ao longo da história européia se modificando, se distanciando do seu solo originário: o mundo humano. Para Husserl, “desde Sócrates, a reflexão toma por tema o homem em sua humanidade específica, o homem como pessoa, como sujeito concreto, construtor de sua história e da história da humanidade” (HUSSERL, 2002, p.88).

A razão técnica e cientificista passou a ocupar o espaço que anteriormente era ocupado pela filosofia. Esse é o novo ente europeu forjado por essa racionalidade, que passa a ser predominante a partir do advento da idade moderna, ente negador da identidade européia autêntica. Antônio Joaquim Severino ao discutir a relação entre filosofia e educação afirma que a filosofia e a educação sempre estiveram próximas, desde o seu nascimento na Grécia clássica, a filosofia se constituiu unida a uma dimensão formativa: “ela já nasceu paideia”(1990, p. 19). No entanto, segundo Severino, na última metade do século vinte essa relação se esmaeceu:

parece ser a primeira vez que uma forte tendência da filosofia considera-se desvinculada de qualquer preocupação de natureza pedagógica, vendo-se tão somente como um exercício puramente lógico. Essa tendência desprendeu-se de suas próprias raízes $\{\ldots\}$ transformando-se numa concepção abrangente que passa a considerar a filosofia como tarefa subsidiária da ciência, só podendo legitimar-se em situação de dependência frente ao conhecimento cientifico, o único conhecimento capaz de verdade e o único plausível fundamento da ação. Desde então qualquer critério do agir humano só pode ser técnico, nunca mais ético ou político. Fica assim rompida a unidade do saber (1990, p. 19).

Com isso, a matematização passou a ser o fundamento da racionalidade filosófica e científica. É neste sentido que Zilles afirma que

as ciências apresentam uma visão do mundo na qual predomina o objetivismo, a quantificação, a formalização, a tecnificação, etc. O mundo da vida, pelo contrário, apresenta-se como um mundo de experiências subjetivas imediatas, dotado em si 
mesmo de sentido e finalidades, pré-dado para explicitação conceptual (2002, p. 52).

Essa racionalidade instaurou uma profunda crise na civilização européia, assolada por guerras, preocupação desmedida com a acumulação de capital, profundas desigualdades sociais. Para Husserl, uma das manifestações dessa crise encontra-se no modo pelo qual as ciências se constituíram, especialmente a partir da influência de Galileu e de Comte. As bases da ciência a partir de então deslocou os resultados científicos da experiência prático-cotidiana para um progresso destituído da preocupação com o humano. Esse modo como as ciências se desenvolveram é chamado por Husserl de objetivismo. Essa orientação desenvolveu uma prática científica que se preocupa em investigar as coisas apenas em sua materialidade e causalidade, sem levar em conta os predicados valorativos das coisas e situações mundanas. Essa prática considera como verdadeira realidade não o mundo apreendido pela experiência, mas o mundo puramente objetivo. O objeto compreendido é assim puro ente físico ou material, destituído de propriedades valorativas e apreendido apenas materialmente.

Para Husserl, as ciências tem se dedicado a estudar somente fatos, tratando os valores e ideais como meros epifenômenos que não fazem parte da realidade mundana. Essa orientação institui um processo de naturalização da investigação científica. Contrapondo à essa perspectiva, Husserl propõe fundamentar as ciências e a filosofia no mundo subjetivo-relativo da experiência sensível. Para Husserl, não se trata de negar a razão, mas restituir-lhe a dimensão critica e humanizadora:

não se trata, pois, com o tema da crise, da verificação de um fracasso da cultura da razão. Pelo contrário, trata-se de renovação, não de inovação. E a renovação é reposta à falência de um projeto. Ela consiste, antes, no regreesso ao sentido original da cultura européia e no cumprimento da exigência de constante renovação que lhe é ínsita, ou seja, de constante reatualização dôo seu ideal de vida. Em suma, a crise detectada não é culminação de uma trajetória da cultura européia que se revelaria, por fim, inviável, mas um abandono de rumo (ALVES, 2006, p. 6). 
Essa renovação e fundamentação é, na verdade, uma refundação da ciência e da filosofia, que se distanciaram do mundo da vida, o que significa que é um projeto de reconhecimento de que os cientistas, os filósofos e as demais pessoas estão interligadas no mundo subjetivo-relativo da experiência sensível, e que as idealidades cientificas sejam construídas sobre as evidências de tais experiências.

O mundo da vida é o mundo da experiência sensível e das associações intersubjetiva. É o mundo sensível-percebido, mundo histórico-social vivido: “é o mundo histórico-cultural concreto, sedimentado intersubjetivamente em usos e costumes, saberes e valores, entre os quais se encontra a imagem do mundo elaborada pelas ciências” (ZILLES, 2002, p. 49). Trata-se do mundo pleno de valores em que a ciência circunscreve a natureza. Com isso, Husserl propõe que a investigação cientifica e filosófica se volte para o mundo da vida em toda a sua complexidade. Para isso Husserl mostra a necessidade de desenvolver uma ideia ampliada de cientificidade que não recusa a complexidade do mundo da vida, mas parte dela para compreender o estabelecimento do objetivismo e para superá-lo.

Com espírito objetivista e pragmátista fa filosofia se distanciou do lebenswelt, do mundo vivido, da atitude crítica e questionadora. É por isso que Husserl propõe que a filosofia e as ciências se voltem para às coisas mesmas, para o seu estado originário e antipredicativo. A filosofia, ao se distanciar do lebenswelt, se distanciou do mundo humano, se fechou no mundo das doutrinas, mundo das interpretações, do já dito e esqueceu de sua finalidade: a compreensão das essências, pois “o Lebenswelt é o âmbito de nossas originárias ‘formações de sentido', do qual nascem as ciências” (ZILLES, 2002, p. 49). Para Husserl, “o erro do objetivismo foi esquecê-lo ou desvalorizá-lo como subjetivo. As teorias lógico-matemáticas substituíram o mundo da vida pela natureza idealizada na linguagem dos símbolos” (ZILLES, 2002, p. 49). O desafio proposta pela fenomenologia para as ciências e a filosofia é o de "recuperá-lo, tirá-lo do anonimato, pois o humano pertence, sem dúvida, ao universo dos fatos objetivos; mas, enquanto pessoas, enquanto $e u$, os homens têm fins, perseguem metas, 
referem-se às normas da tradição, às normas da verdade; normas eternas” (ZILLES, 2002, p. 49), normas que são expressão do mundo humano e não do mundo puramente técnico e objetivo, já que para “o mundo da vida é, para Husserl, um mundo que tem o homem como centro” (ZILLES, 2002, p. 52). As ciências se voltaram se voltaram para o seu próprio desenvolvimento, não importando com as suas consequências, se constituindo em “ciências sem consciência”.

\section{A dimensão ética da crítica ao objetivismo}

O contexto que Husserl desenvolve suas reflexões é o contexto cultural marcado pelo fim da Primeira Guerra Mundial. O que incomoda, impressiona e inquieta Husserl é o caráter trágico deste contexto cultural, marcado pela banalização da vida e pela exaltação da técnica e da ciência. Para Husserl, esse é um contexto profundamente anti-ético. A lógica que orientava as ciências e legitimava as diversas formas de saber científico era dirigida pelas próprias ciências existentes, em especial pelas ciências da natureza. Para Husserl, isso provocou consequências desastrosas para a modernidade: “a própria lógica tornou-se uma ciência especial, em vez de permanecer como doutrina pura e universal da ciência” (apud FABRI, 2006, p. 73). Aqui Husserl pensa tanto a lógica quanto a ética, a partir de uma perspectiva transcendental de sentido (cf. FABRI, 2006, p. 73). Fabri pergunta por que Husserl recorreu à fenomenologia transcendental? E responde afirmando que:

a explicitação do sentido de ser autêntico do domínio e dos conceitos das ciências depende de uma análise da subjetividade constituinte. Tal análise deve considerar a intencionalidade operativa não-temática das práticas científicas. Trata-se, assim, de uma abordagem do sentido e dos horizontes de sentido que estas sempre pressupõem, mas sobre os quais elas sempre se calam (2006, p. 73).

Como se percebe, o que está em questão é a “ideia de ciência numa perspectiva subjetiva, que considera o pensamento que julga, que conhece, que pesquisa, etc” (FABRI, 2006, p. 73). É a ideia de ciência guiada pelo 
pensamento crítico, que questiona e problematiza o fim das atividades científicas, e não uma mera adequação à lógica instrumental e operacional que tem orientado as atividades da ciência. Qual a consequência deste debate para a ética? Podemos dizer que, para Husserl, “a racionalidade prática não pode prescindir do sujeito que valora, que decide, etc.” (FABRI, 2006, p. 73). Para este autor, a atitude teórica emparelha com um autoconhecimento, já que no processo de elaboração da teoria, a tendência é o pesquisador se abandonar às coisas, aos saberes e aos métodos, ignorando tudo o que diz respeito à sua interioridade e a seu ato de operação (cf. FABRI, 2006, p.73). Daí a necessidade de se adentrar mais profundamente na interioridade, que é responsável pelo conhecimento e pela teoria. A interioridade a que Husserl se refere aqui é a interioridade transcendental capaz de compreender tanto a ciência autêntica quanto a teoria autêntica, ou seja, a ciência e a teoria que considerem o mundo da vida (lebenswelt).

Husserl propõe assim, segundo Fabri, que a ética assuma o papel de renovação do homem e da cultura,
pois a guerra revelou a miséria moral e religiosa da humanidade. Ela revelou igualmente, nossa miséria filosófica. A insensatez da cultura é um 'fato' que deve determinar a nossa conduta prática. Ela nos faz refletir sobre questões de princípio, concernentes à vida prática (indivíduo, comunidade e vida racional de modo geral). A ética é uma ciência de princípios porque o indivíduo humano pode acreditar na possibilidade de renovação (justificação racional), mas deve, para tanto, indicar o caminho (método) para que isso se realize (2006, p. 73).

Daí a proposta de Husserl, na obra A crise da humanidade européia e a filosofia, de um retorno da filosofia, e podemos dizer também das ciências, ao ideal grego, ao télos espiritual da humanidade europeia, à identidade européia autêntica, ao pensamento grego clássico como forma de contrapor ao objetivismo que orienta a prática da filosofia, das ciências e da sociedade como um todo. À ética centrada nos parâmetros da matematização, do objetivismo e da impessoalidade, Husserl propõe uma ética voltada para a afirmação da subjetividade, da capacidade do homem de julgar, conhecer e criar. Essa ética tem como referência o lebenswel. 


\section{Contribuições para a educação}

As reflexões de Husserl sobre o objetivismo e sobre a ética apresentam contribuições bastante relevantes para a educação. Tomando como referência essas reflexões, é possível dizer que, para Husserl, a educação precisa ser compreendida como formação, e não como instrumentalização. A instrumentalização transforma o ato de ensinar em um ato mecânico, cuja preocupação é com a memorização, a reprodução, a impessoalização, burocratização, técnica, o objetivismo e a negação do mundo vivido (lebesnwelt). Instrumentalizar é, portanto, o ato de transformar uma atividade que é eminentemente humana, expressão de criação, liberdade, sensibilidade, criticidade e autonomia em um meio técnico, objetivo e calculista. A atividade educativa assim orientada perde sua humanidade, reduz-se a uma coisa, um instrumento, reifica-se e perde sua capacidade de inventividade. Já a formação é entendida como um processo humanizador, um devir civilizatório, uma humanização do homem e do mundo. A formação neste sentido assemelha-se ao ideal educativo grego, à paideia, formação do estado de espírito em que se desabrocha todas as virtualidades humanas. É por isso que, segundo Werner Jaeger, os gregos denominaram de paideia todas as formas e criações espirituais e a sua tradição: “foi sob a forma de paideia, de 'cultura', que os gregos consideraram a totalidade da sua obra criadora” (2001, p.7).

A formação é assim entendida como formação cultural, que é formação para a liberdade e a autonomia. Trata-se de uma formação aberta, ampla, que valoriza o domínio teórico, o desenvolvimento da sensibilidade artística e cultural, o espírito da dúvida e da crítica, a preparação para o mundo do trabalho e o desenvolvimento corporal. É uma educação que a entende não como instrumentalização, um simples treinamento cognitivo, nem um passatempo, mas como elemento formativo.

Pensar a educação na perspectiva da fenomenologia de husserliana é pensá-la para além das velhas práticas pedagógicas que enfatizam o trabalho 
técnico separado do pensamento, e romper com as práticas educativas que ignoram o desenvolvimento humano numa perspectiva de totalidade.

A educação não deve considerar o desenvolvimento da pessoa de modo linear, como acontece com a orientação que adota a teoria do reflexo (estímulo-resposta). Para a fenomenologia, o desenvolvimento da pessoa não é um contínuo, nem o hábito é soma de reflexos. O papel da educação é, sobretudo, apresentar questões, pois, conforme Dilthey,

os filósofos se voltam, de início, em direção ao enigma do mundo e da vida, e é daí que surgem suas concepções da filosofia; qualquer posição ulterior ocupada pelo espírito filosófico se vincula a esta questão fundamental. Todo trabalho filosófico vivo nasce no âmbito desta continuidade e o passado da filosofia age em cada pensador de modo a que este seja conduzido a tomar sua posição nova, mesmo que ele se desespere sabendo que o grande enigma, talvez, jamais seja resolvido (apud VON ZUBEN, 1990, p. 13-14).

O papel da educação é apropriar-se do thaumátzein platônico e aristotélico, assumir uma atitude de espanto, crítica e inquietação com o mundo do objetivismo, da absolutização da ciência e da técnica, compreendendo os seus sentidos e recolocando o lebesnwelt e a subjetividade como referências fundamentais da ação educativa. Isso significa também assumir uma atitude ética voltada para a afirmação da capacidade do homem de julgar, conhecer e criar.

\section{Conclusão}

As concepções de Husserl possibilitam-nos dizer que, para esse filósofo, há a necessidade de nos apropriarmos do thaumátzein, a filosofia sob o seu solo originário, da ética sob a lógica da subjetividade e da educação problematizadora e, a partir daí, reconstruir a filosofia, a ciência e a humanidade autênticas. É por isso que Husserl afirma que “o filósofo sempre deve tentar assenhorar-se do verdadeiro e pleno sentido da filosofia, da totalidade de seus horizontes de infinitude”(HUSSERL, 2002, p. 85). 
Assenhorar-se do sentido da filosofia significa afirmar que "o humano da humanidade superior ou a razão exige, pois uma filosofia autêntica” (HUSSERL, 2002, p. 84.). Uma filosofia autêntica somente é construída com uma razão alargada. Para Merleau-Ponty, é necessário “alargar nossa razão para torna-la capaz de compreender aquilo que em nós e nos outros precede e excede a razão” (1989, p. 151).

Refundar as ciências é igualmente colocar como sua referência básica o homem e suas necessidades e construí-las a partir do mundo-vida. Retomar o ente originário europeu é, segundo Husserl, o caminho para superação do

tão altamente celebrado irracionalismo e, ao mesmo tempo, o lugar para denunciar a ingenuidade daquele racionalismo que é considerado como a racionalidade filosófica pura e simples ... a denominação mais geral que convém a esta ingenuidade é o objetivismo, que se configura nos diferentes tipos de naturalismo, na naturalização do espírito (2002, p. 86).

Problematizar a filosofia e as ciências e retomar o seu ente originário é pensar e fazer filosofia e ciências na perspectiva de um projeto de humanização. Atitude de solicitude e cautela que devemos ter com o outro e com o mundo é colocar a razão a serviço do processo de humanização.

\section{Referências}

ALVES, Pedro Manuel dos. Introdução à tradução portuguesa. In: HUSSERL, Edmund. A crise da bumanidade européia e a filosofia. Lisboa: Centro de Filosofia das Ciências da Universidade de Lisboa, 2006.

DARTIGUES, André. O que é fenomenologia. Rio de Janeiro: Eldorado, 1973.

FABRI, Marcelo. A atualidade da ética hussserliana. In: Revista VERITAS, Porto Alegre, V. 51, jun./2006. p. 69-78.

GILES, Thomas Ranson. História do existencialismo e da fenomenologia. São Paulo: EPU, 1989.

HUSSERL, Edmund. Investigações lógicas: sexta investigação - elementos de uma elucidação fenomenológica do conhecimento. São Paulo: Nova Cultural, 1988. (Os Pensadores).

HUSSERL, Edmund. A ideia da fenomenologia. Lisboa: Edições 70, 1990. 
HUSSERL, Edmund. A crise da humanidade européia e a filosofia. Introdução e tradução de Urbano Zilles. Porto Alegre: EDIPUCRS, 2002.

HUSSERL, Edmund. Meditações cartesianas: introdução à fenomenologia. São Paulo: Madras, 2001.

JAPIASSU, Hilton Ferreira. A crise da razão no ocidente. Disponível em www.sinergia-spe.net/editorialeletronica/autor. Acessado em 30 de março de 2009.

JAEGER, Werner. Paidéia: a formação do homem grego. São Paulo: Martins Fontes, 2001.

MERLEAU-PONTY, Maurice. De Mauss a Claude Lévi-Strauss. In: MerlauPonty. Tradução e notas de Marilena de Souza Chauí. São Paulo: Nova Cultural, 1989.

MOREIRA, Daniel Augusto. O método fenomenológico na pesquisa. São Paulo: Pioneira Tomson, 2002.

SEVERINO, Antonio Joaquim. A contribuição da filosofia para a educação. Em Aberto, Brasília, ano 9, n. 45, jan./mar. 1990.

VON ZUBEN, Newton Aquiles. Filosofia e educação. Em Aberto, Brasília, ano 9, n. 45, jan./mar. 1990.

ZILLES, Urbano. A fenomenologia husserliana como método radical. In: HUSSERL, Edmund. A crise da bumanidade européia e a filosofia. Introdução e tradução de Urbano Zilles. Porto Alegre: EDIPUCRS, 2002.

ZILLES, Urbano. Teoria do conhecimento. Porto Alegre: EDIPURCS, 2003. 